\title{
Turbulent vertical diffusivity in the sub-tropical stratosphere
}

\author{
I. Pisso and B. Legras \\ Laboratoire de Météorologie Dynamique UMR 8539, Paris, France \\ Received: 14 March 2007 - Published in Atmos. Chem. Phys. Discuss.: 16 May 2007 \\ Revised: 12 October 2007 - Accepted: 11 December 2007 - Published: 12 February 2008
}

\begin{abstract}
Vertical (cross-isentropic) mixing is produced by small-scale turbulent processes which are still poorly understood and paramaterized in numerical models. In this work we provide estimates of local equivalent diffusion in the lower stratosphere by comparing balloon borne high-resolution measurements of chemical tracers with reconstructed mixing ratio from large ensembles of random Lagrangian backward trajectories using European Centre for Medium-range Weather Forecasts analysed winds and a chemistry-transport model (REPROBUS). We focus on a case study in subtropical latitudes using data from HIBISCUS campaign. An upper bound on the vertical diffusivity is found in this case study to be of the order of $0.5 \mathrm{~m}^{2} \mathrm{~s}^{-1}$ in the subtropical region, which is larger than the estimates at higher latitudes. The relation between diffusion and dispersion is studied by estimating Lyapunov exponents and studying their variation according to the presence of active dynamical structures.
\end{abstract}

\section{Introduction}

The lower stratosphere can be divided in two parts: an "overworld" region corresponding to the range of potential temperature above the tropical cold point tropopause at about $380 \mathrm{~K}$ in potential temperature $(\theta)$ and an extra-tropical "lowermost stratosphere" (ETLS) below, sharing a range of $\theta$ levels, between $340 \mathrm{~K}$ and $380 \mathrm{~K}$, with the tropical upper troposphere also called Tropical Tropopause Layer (TTL) (Highwood and Hoskins, 1998).

The TTL is separated from the ETLS by the subtropical jets centered in both hemispheres at $200 \mathrm{hPa}$ in pressure or $350 \mathrm{~K}$ in potential temperature. These jets are partial transport barriers to isentropic motion (Del Castillo-Negrete and

Correspondence to: I. Pisso

(ipisso@1md.ens.fr)
Morrison, 1993; Haynes and Shuckburgh, 2000) explaining the observed gradient of long-lived tracers and potential vorticity across them.

Rossby waves are, however, modulating these jets and are capable to generate tropical intrusions of TTL air in the midlatitudes ETLS and, conversely, intrusions of ETLS air, rich in ozone and poor in tropospheric tracers, into the tropical region. Such events transport air masses with mixing ratios of trace gases typical of high latitudes from the lowermost stratosphere into the TTL (Waugh and Polvani, 2000) influencing the chemical composition of the tropical reservoir. This two way stratosphere-troposphere exchange coupling the upper troposphere with the ETLS is a key controlling process for the upper tropospheric ozone budget (Holton et al., 1995), as shown by climate simulations (Sudo et al., 2003).

In the "overworld" lower stratosphere, global observations from space and airborne experiments show that many chemical species have different tropical and extra-tropical mixing ratios along a same isentropic surface and present steep tracer gradients at the edges of the "tropical pipe" (McCormick and Veiga, 1992; Waugh et al., 1994; Waugh, 1996; Neu and Plumb, 1999). However, the tropical pipe extends above $\theta=420 \mathrm{~K}$ while the subtropical jets are below $\theta=380 \mathrm{~K}$. Meridional exchanges are favoured near $\theta=400 \mathrm{~K}$ where there is no significant transport barrier between tropics and extra-tropics (Waugh, 1996; Volk et al., 1996; Rosenlof and McCormick, 1997).

Transport barriers are, however, not impermeable and meridional exchanges occur due to breaking Rossby waves that generate intrusions. This dynamics induces, by chaotic advection, a number of small-scale structures and heterogeneities (Pierrehumbert and Yang, 1993) which have an impact on the composition of the atmosphere and its radiative properties. Although such mechanisms are fairly well understood and can be described with analysed winds, the amount of net irreversible exchange, which requires not only

Published by Copernicus Publications on behalf of the European Geosciences Union. 

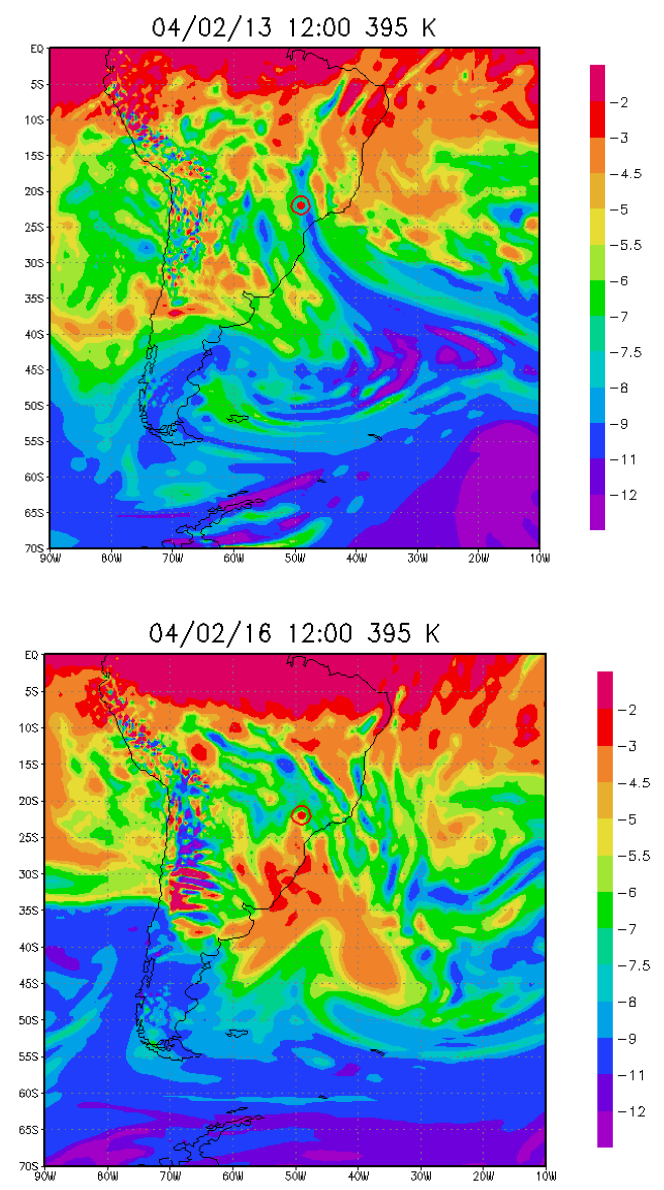

Fig. 1. Potential vorticity maps at $\theta=395 \mathrm{~K}$ from ECMWF analysis over south-America and south-Atlantic. Upper panel shows the meteorological situation on 13 February 2004 at 12:00 UT and lower panel corresponds to 16 February 2004 at 12:00 UT. Units are in $\mathrm{PVU}=10^{6} \mathrm{~m}^{2} \mathrm{~K} \mathrm{~s}^{-1} \mathrm{~kg}^{-1}$. The launching site at Bauru is circled in red.

advection but also mixing of air masses, is still poorly understood and not well represented in meteorological models. Irreversibility results from small-scale turbulent mixing, either due to shear instabilities, convection or gravity wave breaking, occurring at scales too small to be represented in numerical models. General circulation models and chemistrytransport models (CTM) include numerical diffusion that attempts to represent such effects but this is always too large due to limited numerical resolution. It is therefore interesting to investigate the intrinsic effective value of diffusion induced by subgrid scale processes. Such estimates have been provided by comparing Lagrangian calculations with observed distributions of tracers at high and mid-latitudes (Balluch and Haynes, 1997; Legras et al., 2005), reaching estimates in the range $D=0.01-0.1 \mathrm{~m}^{2} \mathrm{~s}^{-1}$, but no study of the subtropical region has been performed so far.

In this work estimates of equivalent diffusion in the lower stratosphere are provided by comparing balloon borne high- resolution measurements of chemical tracers with reconstructed mixing ratio from large ensembles of stochastic Lagrangian backward trajectories using the European Centre for Medium range Weather Forecast (ECMWF) analysed wind fields and outputs from the REPROBUS (REactive Processes Ruling the Ozone BUdget in the Stratosphere) chemistry-transport model. We will focus on the cases of intrusions detected during the HIBISCUS campaign above $15 \mathrm{~km}$

The measurements collected during HIBISCUS tropical campaign and the methods used for analysis are presented in Sect. 2. In Sect. 3, the skill of ensembles of diffusive back trajectories to model transport in the tropics is studied, focusing on the ability to represent synoptic structures related to intrusions. Based on the Lagrangian reconstructions of $\mathrm{O}_{3}$ profiles from the HIBISCUS campaign, the magnitude of turbulent diffusivity in the tropics is estimated. Results are discussed and conclusions are presented in Sect. 4.

\section{Data and methods}

\subsection{The HIBISCUS campaign}

During the HIBISCUS campaign (Pommereau et al., 2007), short balloon flights (SF) carried a Solid State Ozone Sensor instrument (Hansford et al., 2005; Aliwell et al., 2001; Williams et al., 2002). The sensor was developed by the University of Cambridge, and consists of a thin metal oxide (tungsten oxide) layer mounted on a small $(2 \mathrm{~mm} \times 2 \mathrm{~mm})$ ceramic tile. Typical time response of the device is in the order of a few seconds (Pommereau et al., 2007). Sampling frequency is about $1 \mathrm{~Hz}$, yielding about 10000 measurement points per flight, with an effective resolution of about $0.2 \mathrm{~Hz}$. These measurements are compared to those collected by the flights (Pommereau et al., 2007) carrying an ozone sonde (Electro Chemical Cell) from Danish Meteorological Institute (DMI) which reached a mean altitude of $35 \mathrm{~km}$, with a lower resolution. In this study, we focus on the $\mathrm{O}_{3}$ profiles collected during two SF flights.

The first flight considered in this study is the SF2 flight launched on 13 February 2004 under a meteorological situation shown in Fig. 1 where a fresh large intrusion of extratropical air was sitting above the launching site of Bauru (Brazil). The three $\mathrm{O}_{3}$ profiles shown in the first panel of Fig. 2 were collected during the ascent and descent phases of the SF2 flight and during the DMI flight launched the same day, and exhibit clearly defined structures appearing as peaks in the mixing ratio curves. The same panel shows temperature profiles sampled by SF2 during ascent and descent which are nearly identical and reveal a temperature inversion close to the largest $\mathrm{O}_{3}$ peak. The second panel in Fig. 2, shows the water vapour profile collected during the descent, and exhibits a small local maximum correlated with the $\mathrm{O}_{3}$ peak of the descent profile (and a minimum just above 

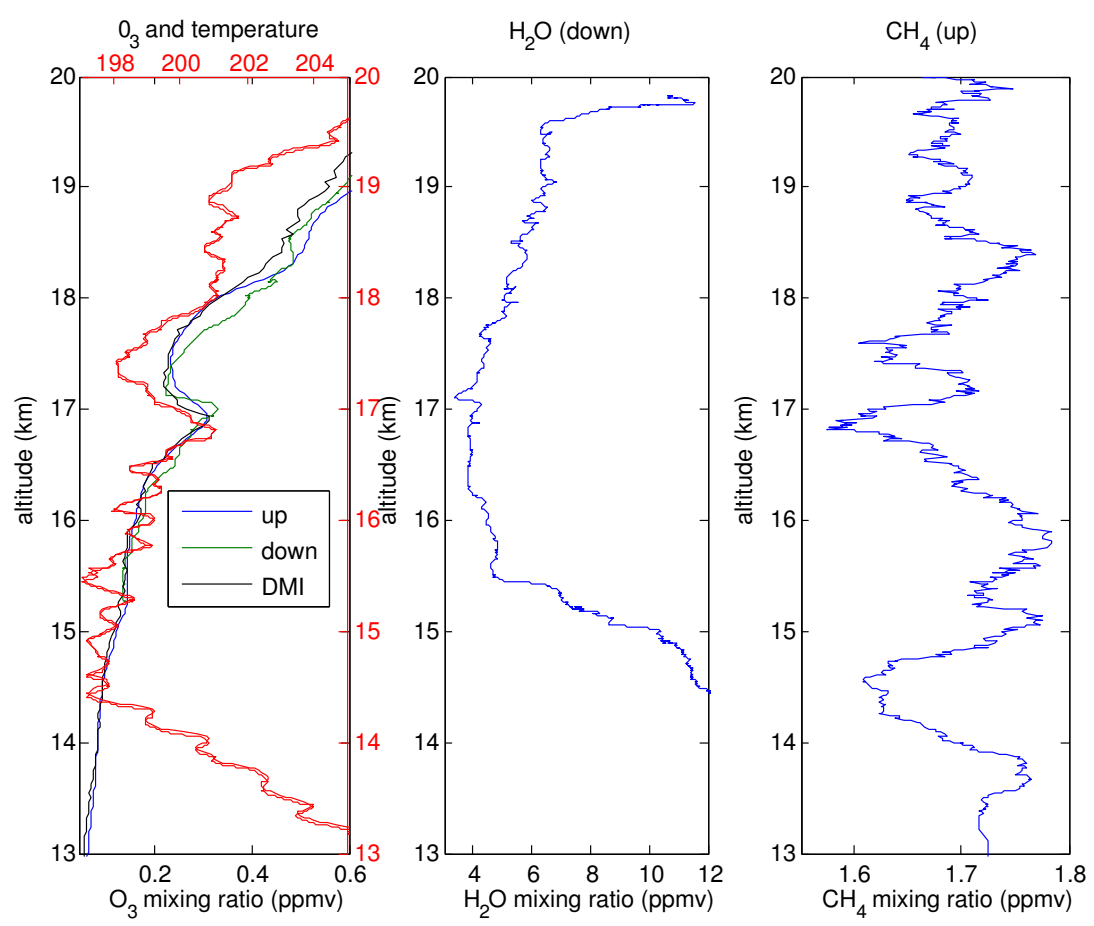

Fig. 2. The first panel compares $\mathrm{O}_{3}$ profile obtained during ascent (blue) and descent (green) of the SF2 flight on 13 February 2004 with temperature profile (red) collected during the same flight and $\mathrm{O}_{3}$ profile measured by DMI ozone sonde (black). Second panel shows water vapour collected during SF2 descent and third panel shows methane collected during SF2 ascent. SF2 balloon was launched at 20:19 UT on 13 February. DMI ozone sonde was launched at 22:35 UT the same day.

where $\mathrm{O}_{3}$ drops). The third panel shows the $\mathrm{CH}_{4}$ profile collected during the ascent and exhibits an absolute minimum around $17 \mathrm{~km}$ that coincides with the $\mathrm{O}_{3}$ peak of the ascent phase. The large values of $\mathrm{O}_{3}$ mixing ratio in the peaks with respect to the background values and the higher value in water vapour and lower value in $\mathrm{CH}_{4}$ suggest the presence of a layer of extra-tropical intrusion.

SF1 was launched three days later, on 16 February, while the intrusion had ended but left significant remains of extra tropical air in the region surrounding Bauru as suggested by the meteorological situation shown in Fig. 1. Figure 3 shows $\mathrm{O}_{3}$ mixing ratio profiles collected during the ascent and descent phases of SF1 flight and during the ascent of DMI flight launched at 00:08 UT the same day. The three $\mathrm{O}_{3}$ profiles show peaks in mixing ratio values at different altitudes between 17.5 and $18 \mathrm{~km}$. The SF1 ascent profile shows the peak shifted down with respect to the SF1 descent profile, and in the DMI profile the peak is even lower. The temperature collected during SF1 ascent and descent is also drawn showing almost no difference between ascent and descent and an inversion around $18 \mathrm{~km}$ located close to the three $\mathrm{O}_{3}$ peaks. This suggests a less stable situation than during SF2 flight, with an $\mathrm{O}_{3}$ rich layer sloping vertically and moving during the day. This is further suggested by Fig. 4 showing the potential temperature as a function of altitude (first panel) and the $\mathrm{O}_{3}$ mixing ratio as a function of potential tempera- ture. The right panel shows that the SF2 ozone peak found near $17 \mathrm{~km}$ in the left panel of Fig. 2 is $10 \mathrm{~K}$ wide in potential temperature between $390 \mathrm{~K}$ and $400 \mathrm{~K}$ and the left panel shows that this layer exhibit a stable vertical gradient of potential temperature. Conversely, the SF1 ozone peak just below $18 \mathrm{~km}$ in Fig. 3 has a smaller $5 \mathrm{~K}$ extent in potential temperature near $410 \mathrm{~K}$ and is associated with a layer which exhibits a weak inversion of potential temperature. This suggests that the ozone layer captured by SF2 is well-defined in the horizontal and the vertical direction while the ozone layer of SF1 is a more fugitive structure.

\subsection{Diffusive backward trajectories}

Because the typical horizontal/vertical aspect ratio of tracer structures in the stratosphere is large (Haynes and Anglade, 1997), the main contributor to mixing is the vertical turbulent motion. This motivates the representation of small-scale turbulence in Lagrangian calculations as a vertical stochastic perturbation on the velocity field. The stochastic perturbation takes into account the turbulent motions occurring at unresolved scales. It is assumed that the overall effect of turbulence in a spatial scale smaller than the advecting fields grid has time scales much smaller than the time step of advection and hence can be approximated as a diffusive process. The displacement of an individual particle due to the perturbation 


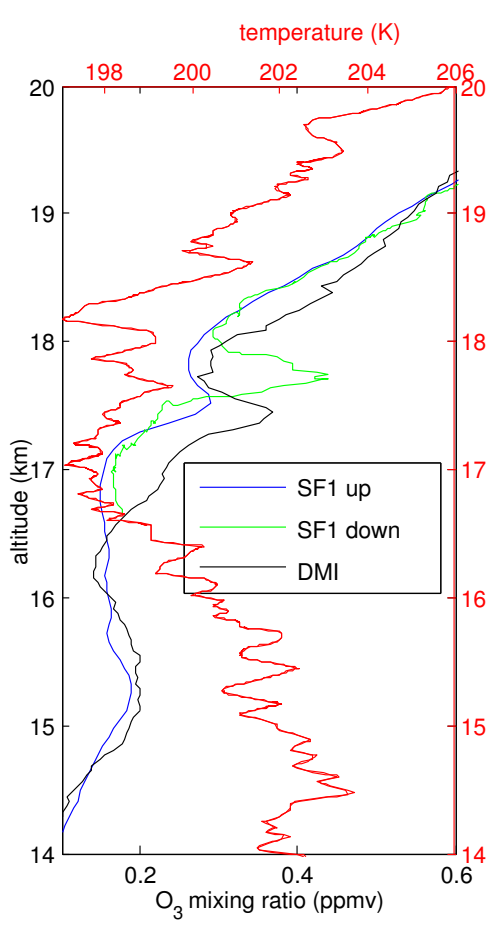

Fig. 3. Comparison of $\mathrm{O}_{3}$ profiles obtained during ascent and descent of the SF1 flight on 16 February 2004 (blue and green) and DMI sonde the same day (black). Red curve represents temperature profile corresponding to SF1 flight. SF1 balloon was launched at 20:24 UT on 16 February. DMI ozone sonde was launched at 00:08 UT the same day.

and the advecting velocity reads:

$\delta \boldsymbol{x}=\boldsymbol{u}(\boldsymbol{x}, t) \delta t+\boldsymbol{k} \delta \eta(t)$

where $\boldsymbol{k}$ is the vertical unit vector and $\delta \eta(t)=\sum_{i=1}^{m} w_{i} \frac{\delta t}{m}$ is a sum of the product of a white noise process $w_{i}$ by the reduced time step $\frac{\delta t}{m}$. In this work, independent perturbations are applied to each member of a large ensemble of backward trajectories and we take $m=50$.

The solution to the advective diffusive equation

$\frac{\partial C}{\partial t}+\boldsymbol{u}(\boldsymbol{x}, t) \cdot \nabla C=D \nabla^{2} C$

for impulsive initial conditions yields that the standard deviation of the positions of a diffused cloud of particles released at time $t=0$ is $\sigma=\sqrt{2 D t}$, where $D$ is the diffusivity. The random variable $w_{i}$ used to generate the stochastic perturbation $\delta \eta(t)$ in Eq. (1) is uniform, with zero mean and variance $<w_{i}^{2}>$ such that

$D=\frac{1}{2}<w_{i}^{2}>\frac{\delta t}{m}$

This technique is related to the solution to Eq. (2) by the Green function technique to obtain the field caused by a distributed source (i.e. the concentration at a time $s$ previous
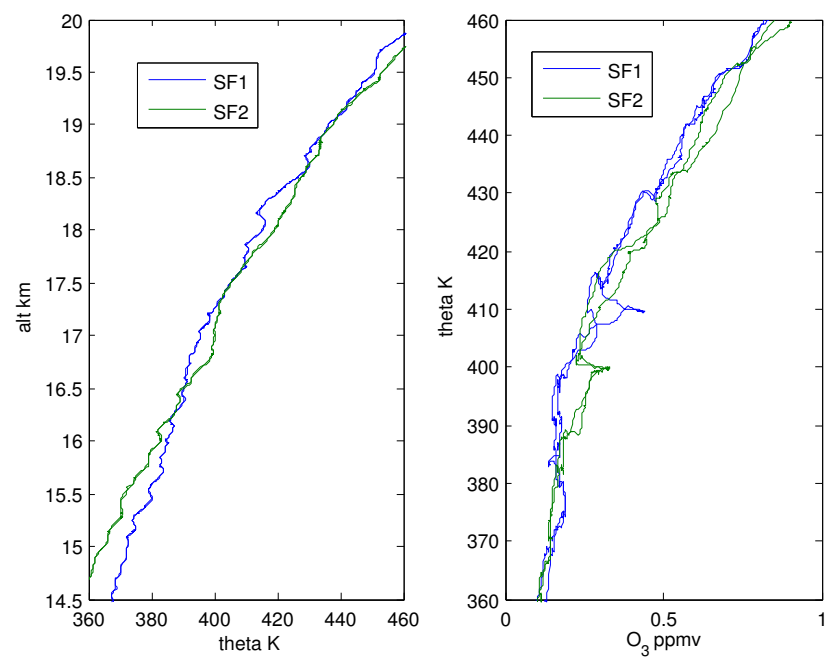

Fig. 4. Potential temperature $\theta$ as a function of altitude and $\mathrm{O}_{3}$ mixing ratio as a function of $\theta$ for SF1 and SF2 flights, for both ascent and descent.

to $t)$. If $G(\boldsymbol{x}, t ; \boldsymbol{y}, s)$ is the mixing ratio at the point $\boldsymbol{x}$ and time $t$ caused by a unit point source at the point $y$ and time $s$, then the field at $(\boldsymbol{x}, t)$ caused by a source distribution $C(\boldsymbol{y}, s)$ can be described as the integral

$C(\boldsymbol{x}, t)=\int G(\boldsymbol{x}, t ; \boldsymbol{y}, s) C(\boldsymbol{y}, s) d^{3} \boldsymbol{y}$

where $G(\boldsymbol{x}, t ; \boldsymbol{y}, s)$ satisfies the two Eqs. (Morse and Feshbach, 1953; Legras et al., 2005):

$$
\begin{aligned}
\frac{\partial G}{\partial t}+\boldsymbol{u}(\boldsymbol{x}, t) \cdot \nabla_{\boldsymbol{x}} G & -\frac{D}{\rho(\boldsymbol{x}, t)} \nabla_{\boldsymbol{x}}\left(\rho(\boldsymbol{x}, t) \nabla_{\boldsymbol{x}} G\right) \\
= & \frac{1}{\rho(\boldsymbol{y}, s)} \delta(t-s) \delta^{3}(\boldsymbol{y}-\boldsymbol{x}), \\
\frac{\partial G}{\partial s}+\boldsymbol{u}(\boldsymbol{y}, s) \cdot \nabla_{\boldsymbol{y}} G & +\frac{D}{\rho(\boldsymbol{y}, s)} \nabla_{\boldsymbol{y}}\left(\rho(\boldsymbol{y}, s) \nabla_{\boldsymbol{y}} G\right) \\
= & -\frac{1}{\rho(\boldsymbol{x}, t)} \delta(t-s) \delta^{3}(\boldsymbol{y}-\boldsymbol{x}),
\end{aligned}
$$

which are written in the general compressible form with $\rho$ the fluid density. Here the derivatives are taken with respect to the final coordinates $\boldsymbol{x}$ and $t$ for Eq. (5) and with respect to the initial coordinates $\boldsymbol{y}$ and $s$ for Eq. (6), which is wellposed for backward integration in time. Equation (1) provides a numerical solution to Eq. (6) for an arbitrary selection of end points. For a more detailed discussion, see Holzer and Hall (2000); Issartel and Baverel (2003); Dexheimer and Bowman (2004).

\subsection{TRACZILLA}

Reverse integrations of trajectories initialised along each transect have been performed with TRACZILLA, a modified version of FLEXPART (Stohl et al., 2005) which uses 

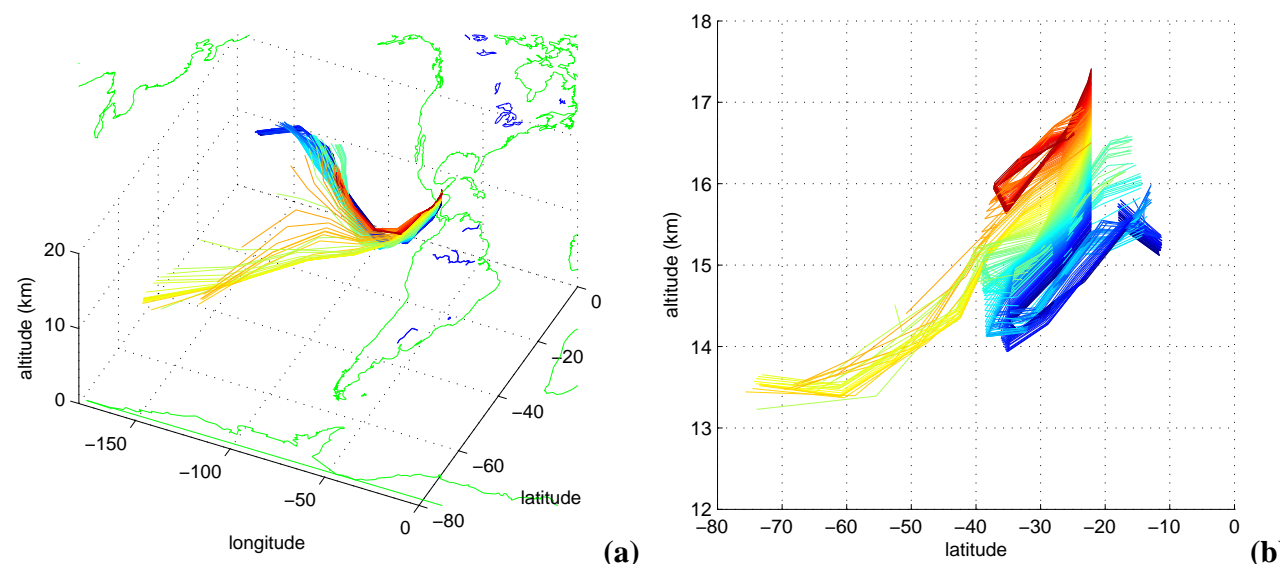

Fig. 5. Back trajectories initialised along SF2 balloon track and calculated over 9 days. (a) Left panel: three dimensional representation. (b) Right panel: projection on the vertical-meridional axis. Colour code shows the altitude of the initial point of the trajectory.

ECMWF winds at $1^{\circ}$ horizontal resolution and on 60 hybrid levels with 3-h resolution obtained by combining analysis available every $6 \mathrm{~h}$ with short time forecasts at intermediate times (3-h resolution). The modifications from FLEXPART advection scheme consists mainly in discarding the intermediate terrain following coordinate system and in performing a direct vertical interpolation of winds, linear in log-pressure, from hybrid levels. The vertical velocities used in this work are computed by the FLEXPART preprocessor using a mass conserving scheme in the hybrid ECMWF coordinates. The model uses a fixed time step $\delta t=900 \mathrm{~s}$. The release size $N$ of the ensemble of trajectories used in this work is either $N=500$ or $N=2000$. Time lag between parcel release is either $1 \mathrm{~s}$ or $30 \mathrm{~s}$ along the balloon track. We use the balloon GPS data and the on-board pressure sensor to locate the launching point of each parcel, in the horizontal and the vertical.

\subsection{REPROBUS}

Chemical mixing ratios where interpolated from REPROBUS 3-D output fields. REPROBUS (REactive Processes Ruling the Ozone BUdget in the Stratosphere) is a three-dimensional chemical-transport model with a comprehensive treatment of gas-phase and heterogeneous chemical processes in the stratosphere (Lefèvre et al., 1994, 1998). Long-lived species, including ozone, are advected by a semi-Lagrangian scheme (Williamson, 1989) forced by the ECMWF wind analysis. The model is integrated on 42 hybrid pressure levels that extend from the ground up to $0.1 \mathrm{hPa}$, with a horizontal resolution of $2^{\circ}$ and a time resolution of $3 \mathrm{~h}$. The simulation used in this study was initialised on 1st April 2002 taking ozone field from ECMWF analysis and other compounds from climatology. Owing to the elapsed time between this initial state and the HIBISCUS campaign, it can be safely argued that the ozone field of the REPROBUS model in February 2004 is independent of the initialisation.

\section{Results}

\subsection{SF2 and active intrusion}

\subsubsection{Back trajectories}

In order to study the origin and dynamical history of the sampled air, back-trajectories have been initialised starting from each measure point along SF2 flight track between 15 and $17.5 \mathrm{~km}$ above Bauru.

Figure 5a shows the 3-D back trajectories calculated over 9 days before the SF2 flight without added diffusion, and Fig. 5b shows the same set of back trajectories projected onto the latitude-altitude plane. For most of the trajectories, the air comes from regions located north of the launching site and altitudes above $15 \mathrm{~km}$. However, the group of air parcels sampled between 16 and $17 \mathrm{~km}$ (in yellow) originates from latitudes below $70 \mathrm{~S}$ and altitudes below $14 \mathrm{~km}$. This is consistent with the peak of $\mathrm{O}_{3}$ mixing ratio measured by SF2 instruments at $17 \mathrm{~km}$ and suggests that the mixing ratio peak is due to the layering of an extra-tropical air intrusion across the subtropical barrier. Figure 6 supports this interpretation by showing that the $400 \mathrm{~K}$ isentropic surface is rising towards the equator (the isobars are descending in $\theta$-coordinate) and that the ozone gradient is directed towards the pole on this surface, although its magnitude is much smaller in the southern summer hemisphere than in the northern winter hemisphere.

Figure 7 compares the $\mathrm{O}_{3}$ reconstruction from this set of non diffusive trajectories with $\mathrm{O}_{3}$ measurements during SF2 flight. In spite of the very large noise inherent to this reconstruction, we see that the peaks between 15 and $16 \mathrm{~km}$, at $17 \mathrm{~km}$ and at $19 \mathrm{~km}$ are all associated with bumps in the 

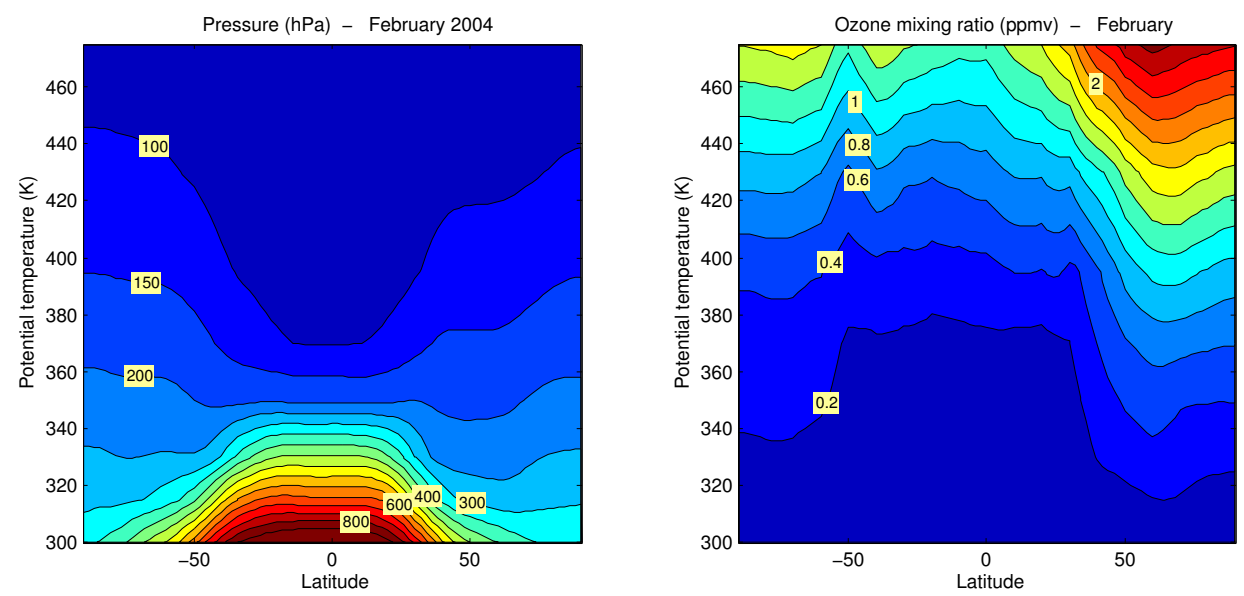

Fig. 6. Left panel: Pressure (hPa) for February 2004. Data are from the operational ECMWF analysis averaged over the whole month and in longitude. Right panel: Ozone mixing ratio (ppmv) for February. Data are interpolated from Fortuin and Kelder (1998) using the ECMWF meteorological analysis of February 2004.

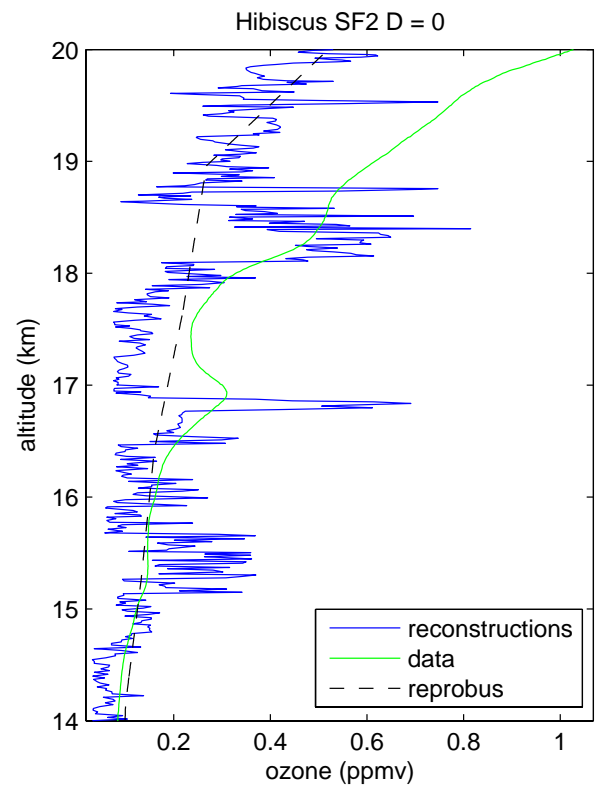

Fig. 7. Deterministic reconstruction of SF2 ozone profile without diffusion. Each measurement point is represented by one trajectory. Vertical axis is the altitude along the balloon track. The green curve represents the ozone profile measured by SF2 flight. Lagrangian reconstructions without diffusion (in blue) are much rougher than measured profiles. The black dashed line shows the $\mathrm{O}_{3}$ mixing ratios interpolated from global REPROBUS chemical fields on measurement locations.

observed profile. The depleted layer between 17 and $18 \mathrm{~km}$ is also seen in the observed profile. All these features are, however, strongly exaggerated in the reconstruction. The upper part of the reconstructed profile, above $18 \mathrm{~km}$ tends to follow the REPROBUS profile and to depart from the observations, resulting in an underestimation of about $50 \%$. We meet here one of the fundamental limitations of reconstructions which is that they are able to regenerate the small scales of the tracer but they depend on the accuracy of the supporting CTM or chemical data for the mean gradients. In fact, REPROBUS underestimates ozone in most of the lower tropical and subtropical stratosphere (G. Berthet, personal communication).

\subsubsection{Diffusive reconstructions}

In order to estimate the vertical diffusivity coefficient, we compare now the values of $\mathrm{O}_{3}$ mixing ratio measured by SF2 sonde with diffusive reconstructions with the TRACZILLA model. Figure 8 shows the reconstructions obtained with a range of diffusivity from $D=10^{-3} \mathrm{~m}^{2} \mathrm{~s}^{-1}$ to $D=1 \mathrm{~m}^{2} \mathrm{~s}^{-1}$. In addition to adding vertical diffusion, we have also filtered the reconstructions with a running centered average over $5 \mathrm{~s}$ in order to simulate the response function of the instrument (Pommereau et al., 2007).

In the lower layers, corresponding to the troposphere, the mean reconstructed $\mathrm{O}_{3}$ is closer to the measurements than the prediction of REPROBUS. However, small diffusivity $D \leq 0.1 \mathrm{~m}^{2} \mathrm{~s}^{-1}$ generates a number of fluctuations which are not observed. It is only for $D=0.5 \mathrm{~m}^{2} \mathrm{~s}^{-1}$, that the fluctuations are reduced to the level of the observations below $14 \mathrm{~km}$.

Above the tropopause, the peak in $\mathrm{O}_{3}$ mixing ratio located between 16 and $17 \mathrm{~km}$, corresponding to the extra-tropical intrusion, is reproduced in all reconstructions but overestimated for values of $D$ below $0.1 \mathrm{~m}^{2} \mathrm{~s}^{-1}$. The difference with the measured values in this layer is of more than $100 \%$ for the values $D=0.001 \mathrm{~m}^{2} \mathrm{~s}^{-1}$ and $D=0.01 \mathrm{~m}^{2} \mathrm{~s}^{-1}$. However, the slope of the curve, which represents the gradient of mixing ratio, is too steep for $D=0.1 \mathrm{~m}^{2} \mathrm{~s}^{-1}$. It is again with 

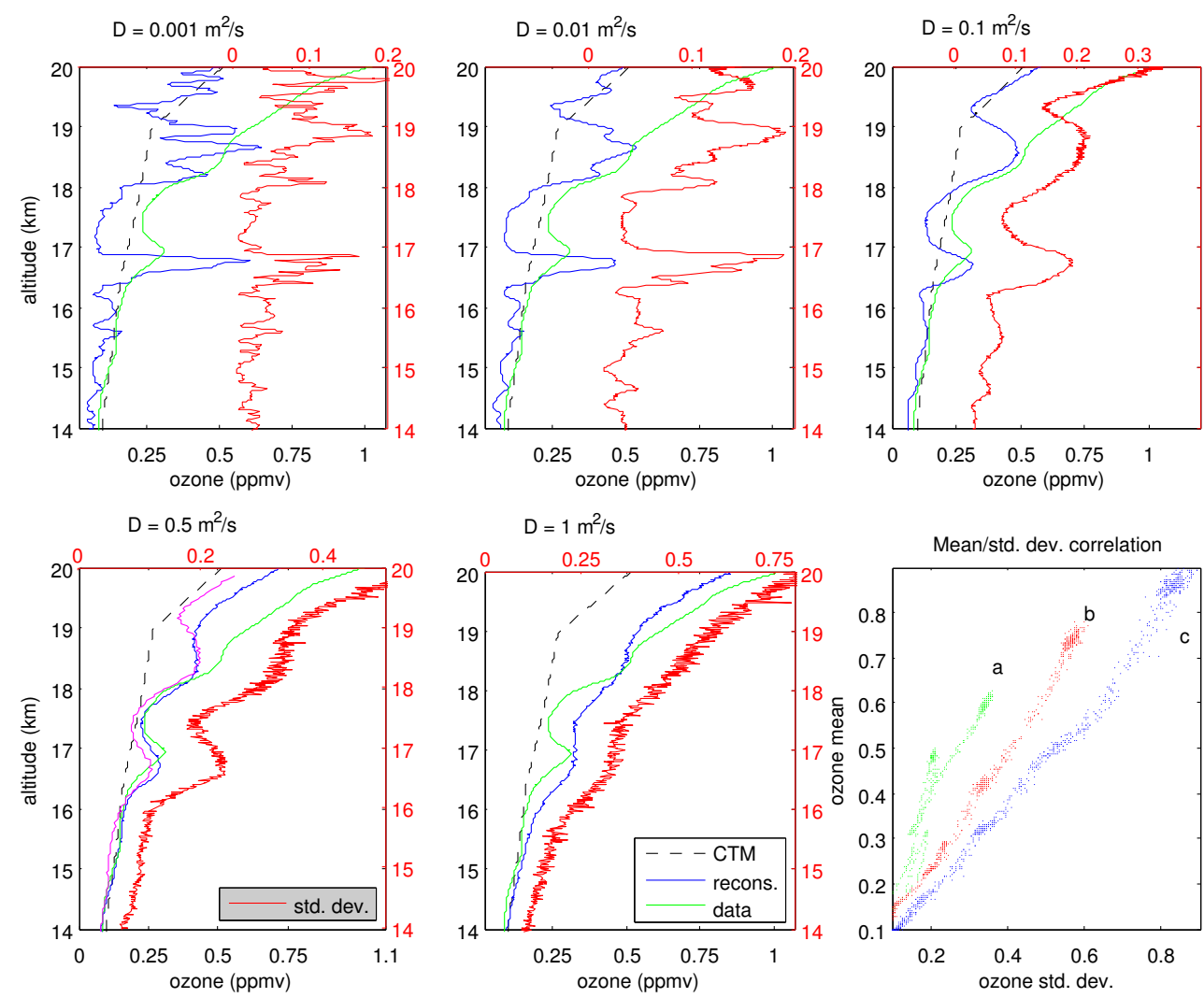

Fig. 8. Blue curves show diffusive reconstructions of SF2 ozone profile for values of D ranging from $10^{-3} \mathrm{~m}^{2} \mathrm{~s}^{-1}$ (upper left panel) to $1 \mathrm{~m}^{2} \mathrm{~s}^{-1}$ (lower centre panel). Vertical axis is the altitude of initialisation points. Green curves represent the ozone profile measured by SF2 flight and black dashed lines show the $\mathrm{O}_{3}$ mixing ratios interpolated from global 3-D REPROBUS chemical fields. Red curves show the standard deviation of $\mathrm{O}_{3}$ mixing ratio (in ppmv) associated with each individual cloud of trajectories. Values are read from the upper horizontal axis. The magenta curve in the lower left panel shows the reconstruction obtained with horizontal diffusion $D_{H}=250000 \mathrm{~m}^{2} \mathrm{~s}^{-1}$. Lower right panel shows the correlation between the mean and the standard deviation for the diffusive reconstructions along SF2 profile calculated for values of diffusivity of $0.1 \mathrm{~m}^{2} \mathrm{~s}^{-1}$ (a), $0.5 \mathrm{~m}^{2} \mathrm{~s}^{-1}$ (b) and $1 \mathrm{~m}^{2} \mathrm{~s}^{-1}$ (c).

$D=0.5 \mathrm{~m}^{2} \mathrm{~s}^{-1}$ that we reach the best agreement with the observations both for the peak at $17 \mathrm{~km}$ and the depleted layer between 17 and $18 \mathrm{~km}$. The position of the peak is only shifted by $200 \mathrm{~m}$ in the reconstruction.

Above $18 \mathrm{~km}$, where REPROBUS departs significantly from the observations, the reconstructions exclude any value less than $0.1 \mathrm{~m}^{2} \mathrm{~s}^{-1}$ which produces too large, unobserved fluctuations. On the other side, the closeness between observations and $1 \mathrm{~m}^{2} \mathrm{~s}^{-1}$ profile is only a spurious result that compensates the under-prediction of ozone by REPROBUS by increased diffusion along the vertical gradient. Small wiggles on the reconstructed curve are due to sampling effects which increase with $D$ in the reconstructions.

The profile of the tracer standard deviation within the cloud of points associated with each parcel is also shown in Fig. 8. It grows with diffusion as the cloud of points invades a wider range of altitudes and latitudes. Lower-right panel shows that, for several values of $D$, the standard deviation is well correlated with the mean. The fact that $\frac{\sqrt{\left\langle C^{2}\right\rangle}}{\langle C\rangle} \approx$ con- stant is consistent with fluctuations $C^{\prime}$ being due to displacements in the vertical and horizontal gradients of $C$ rather than to chemical effects.

In order to test our assumption that mixing is mainly crossisentropic we have also performed an additional calculation where the vertical diffusion $D$ is set to zero and replaced by a horizontal diffusion $D_{H}$. The lower left panel of Fig. 8 shows that $D_{H} \approx 250000 \mathrm{~m}^{2} \mathrm{~s}^{-1}$ is needed to match the reconstructed profile obtained with $D=0.5 \mathrm{~m}^{2} \mathrm{~s}^{-1}$. The large ratio, of the order 500000 between $D_{H}$ and $D$ is consistent with the examination of the dispersion of close trajectories. Parcels initially distant of $10 \mathrm{~m}$ in the vertical along the SF2 profile are separated by an average distance of $9 \mathrm{~km}$ after $30 \mathrm{~h}$ of backward integration without diffusion. This means a vertical shear $0.008 \mathrm{~s}^{-1}$. Parcels initially separated by $2.5 \mathrm{~km}$ in the horizontal hardly separate by more than $5 \mathrm{~km}$ over the same period, which provides an upper bound for horizontal deformation or shear as $4.10^{-6} \mathrm{~s}^{-1}$. It thus appears that the purely horizontal dispersion is very weak in the 


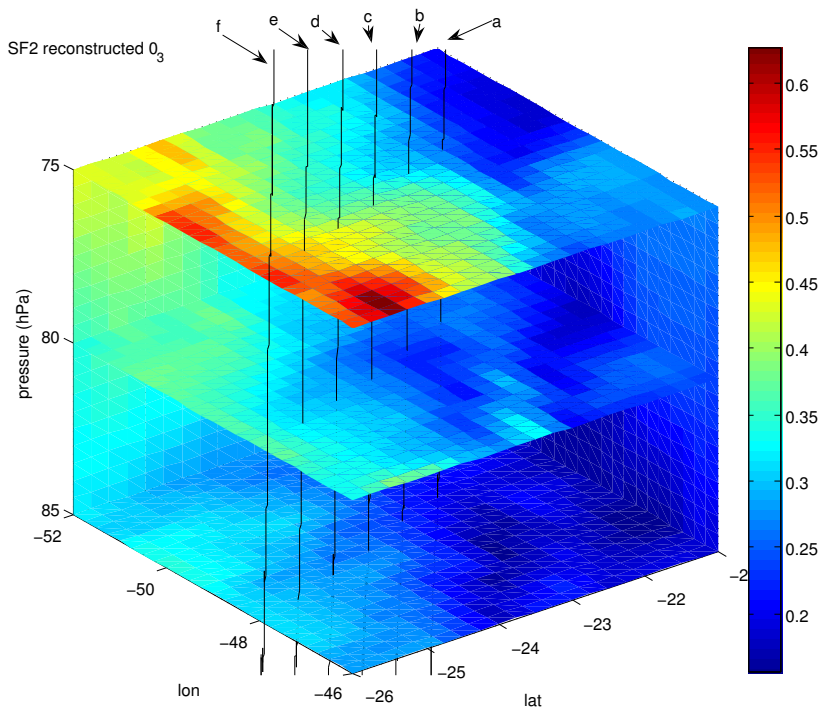

Fig. 9. Three dimensional distribution of $\mathrm{O}_{3}$ in a neighbourhood of the segment supporting the peak on 16 February. The region considered corresponds to three pressure levels $(85,80$ and $75 \mathrm{hPa})$ from $21 \mathrm{~S}$ to $26 \mathrm{~S}$ in latitude and $46 \mathrm{~W}$ to $52 \mathrm{~W}$ in longitude. Ensembles of diffusive backward trajectories with a value of $\mathrm{D}$ of $0.1 \mathrm{~m}^{2} \mathrm{~s}^{-1}$ were used to reconstruct the $\mathrm{O}_{3}$ mixing ratio in a $1.5^{\circ}$ horizontal grid and the result was interpolated on a $0.25^{\circ}$ horizontal grid. The vertical lines represent the actual and shifted balloon tracks used to produce Fig. 10. A region of low $\mathrm{O}_{3}$ is apparent at the level $80 \mathrm{hPa}$ over the launching site. Colour code represents $\mathrm{O}_{3}$ mixing ratio in ppbv. Vertical lines are the locations of shifted reconstructions shown in Fig. 10.

considered case, at least based on the ECMWF analysis. We have checked our calculations by using the same numerical tools on high latitude winter ozone profiles for which the diffusivity ratio is found to be 60000 , compatible with a vertical to horizontal shear ratio of 250 as estimated by Haynes and Anglade (1997) in the lower stratosphere.

Both estimates of vertical and horizontal diffusions are similar to those of Hegglin et al. (2005) in the lower stratosphere, although we believe that the agreement is somewhat coincidental for the horizontal diffusion. The calculation of Hegglin et al. (2005) includes the effect of synoptic perturbations while our estimates is related to subgrid-scale effects.

\subsection{SF1 and decaying intrusion}

Figure $1 \mathrm{~b}$ shows that on 16 February, the active phase of the intrusion dominating on 13 February has ended and the region surrounding Bauru is filled with numerous remains as patches of high PV. This suggests that tracers are also distributed as patches and that lamination might occur over a small area rather than over a broad domain like on 13 February. This suggests also that reconstructions will perform less accurately in that case.
Indeed, diffusive reconstructions with a small value of D of $0.1 \mathrm{~m}^{2} \mathrm{~s}^{-1}$, which generally tend to exaggerate features in observed profiles do not show even one hint of the peak of $\mathrm{O}_{3}$ mixing ratio in the profile of SF1 flight as seen in Fig. 10a.

In order to investigate the causes of this discrepancy, ensembles of diffusive backward trajectories have been initialised not only at measured locations along the balloon track but also at other locations in its neighbourhood.

Figure 9 shows a 3-D neighbourhood (21 S to $26 \mathrm{~S}$ in latitude, $46 \mathrm{~W}$ to $52 \mathrm{~W}$ in longitude and $85 \mathrm{hPa}$ to $75 \mathrm{hPa}$ in pressure) of the SF1 flight segment over which the peaks were detected. This figure is generated by performing diffusive reconstructions with $D=0.1 \mathrm{~m}^{2} \mathrm{~s}^{-1}$ in three horizontal planes at three pressure levels: $85 \mathrm{hPa}(17.25 \mathrm{~km})$, $80 \mathrm{hPa}\left(17.65 \mathrm{~km}\right.$, around the maximum of $\left.\mathrm{O}_{3}\right)$ and $85 \mathrm{hPa}$ $(18.15 \mathrm{~km})$, respectively. It is clear that Bauru is, according to this map, located in a region with $\mathrm{O}_{3}$ less than $0.3 \mathrm{ppbv}$ just north of a large meridional gradient in ozone concentration with values of the order of $0.4 \mathrm{ppbv}$ at $200 \mathrm{~km}$ from the launch site. The accuracy in the location of such gradient depends both on the chemical initialisation field and on the advecting winds. Displacements of the order of tens of kilometres are very common when comparing observed and reconstructed structures along aircraft tracks (Legras et al., 2005, eg.). It is likely that the missing bump on the SF1 reconstructed profile could be found in the neighbourhood of Bauru, on the southern side.

Hence, we have reconstructed the $\mathrm{O}_{3}$ profile over the 5 profiles along the vertical lines in Fig. 9 distributed horizontally over a segment running between the launch site at $(22.5 \mathrm{~S}, 49.5 \mathrm{~W})$ and $(25.85 \mathrm{~S}, 47.46 \mathrm{~W})$ where reconstructed $\mathrm{O}_{3}$ is high. The reconstructed profiles in Fig. 10b-f show that a peak of $\mathrm{O}_{3}$ near $18 \mathrm{~km}$ is obtained in panels (d) to (f). This peak is larger than the observed one and is vertically shifted by about $300 \mathrm{~m}$. Different values of $D$ yield different structures in the distribution on $\mathrm{O}_{3}$ in this region. The determination of a unique value for $D$ relies on the identification and reconstruction of measured tracer structures, and here additional hypothesis are needed to constrain the values of diffusivity. Hence, it is not possible from these reconstructions to estimate $D$ accurately.

\subsection{Detecting dynamical boundaries}

Regions of high dispersion in the flow (i.e., rapid separation of pairs of particles) are characterised by maxima of Lyapunov exponents (Pierrehumbert and Yang, 1993; Legras et al., 2005). Finite time Lyapunov exponents, which describe the transformation of an infinitesimal spherical cloud surrounding a particle at time $t_{0}$ into an ellipsoid at time $t_{1}$ in a local reference frame relative to the particle, have been calculated along the balloon tracks in order to study the dynamical history of the sampled air. The calculation of the three local Lyapunov exponents around a deterministic particle trajectory is performed by using a triad of orthogonal 

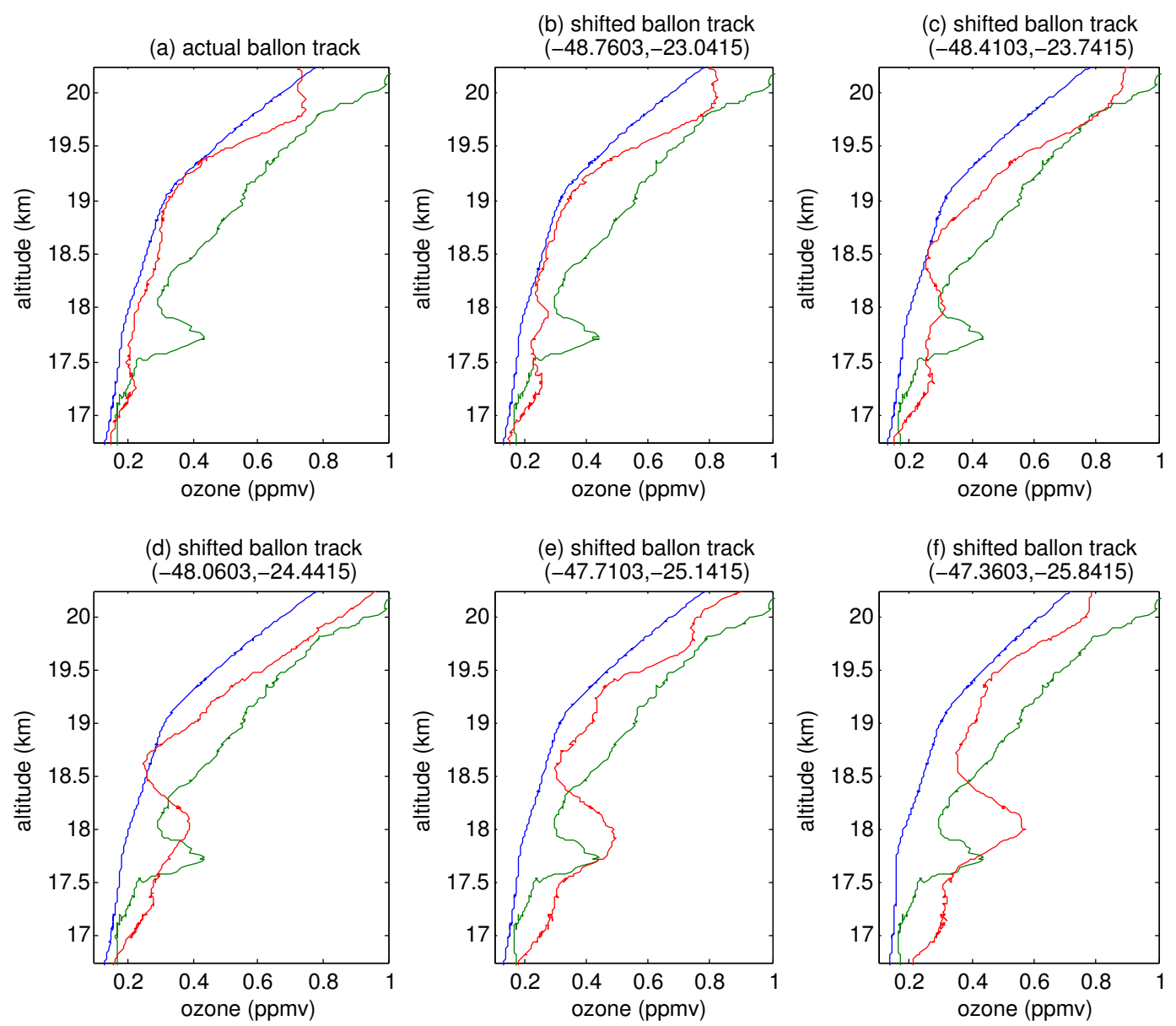

Fig. 10. $\mathrm{O}_{3}$ diffusive reconstructions for the SF1 flight on 16 February 2004 (descent) performed with a diffusivity of $0.1 \mathrm{~m}^{2} \mathrm{~s}^{-1}$. Upper left panel corresponds to the actual flight track, over the launching site at $(49.03 \mathrm{~W}, 22.36 \mathrm{~S})$. The following panels show diffusive reconstructions initialised by shifting the actual balloon track along a line running from the launch site to where reconstructed $\mathrm{O}_{3}$ is high as indicated in Fig. 9. Green: observed ozone profile; blue: REPROBUS profile at the launch site; red: reconstructed profile at shifted location. A peak at $18 \mathrm{~km}$ is observed in the lower three panels.

displacement around the initial position. Such triads are further distributed around each measured point, on a cubic grid centered on that point. The initial separations determining the size of the cube are $10 \mathrm{~m}$ in the vertical and $2500 \mathrm{~m}$ in the horizontal (based on the typical stratospheric aspect ratio of stratospheric tracer layers Haynes and Anglade, 1997). Renormalisation of the triads is performed every $24 \mathrm{~h}$ according to the standard algorithm of Benettin et al. (1980) and the Lyapunov exponents, which stabilise after three to five days, are averaged over the cube surrounding each point.

Influence of long range advection is seen as strong gradients and peaks in reconstructed mixing ratio profiles of tracers. Strong strain is represented by peaks in the Lyapunov exponents.

The first panel in Fig. 11 shows the exponents for SF2 flight focusing on the vertical range of the extra tropical tropical intrusion. The peaks at $16.5 \mathrm{~km}$ and slightly below $17 \mathrm{~km}$ mark regions of high stretching where gradients intensify or- thogonally to the stretching direction. They mark the boundaries of the intrusion, where two backward trajectories separate rapidly. Conversely, the minima correspond to regions of the flow with small separation rates of back trajectories. These are associated with the core of the intrusion, where dispersion is small as suggested from Fig. 5.

The second panel of Fig. 11 shows two different diffusive reconstructions of $\mathrm{O}_{3}$ mixing ratio along the same flight track, corresponding to diffusions of 0.1 and $0.5 \mathrm{~m}^{2} \mathrm{~s}^{-2}$, compared to the measured profile, showing that the location of largest gradient agrees very well with the peaks of the Lyapunov exponent. Therefore, the surfaces limiting the intrusion (above and below) where the contact is established between air masses coming from different origins can be considered as dynamical boundaries. This is further demonstrated in the third panel of Fig. 11 which shows the reconstruction from a non diffusive cloud of points initialised around each parcel at the points used for Lyapunov exponent 

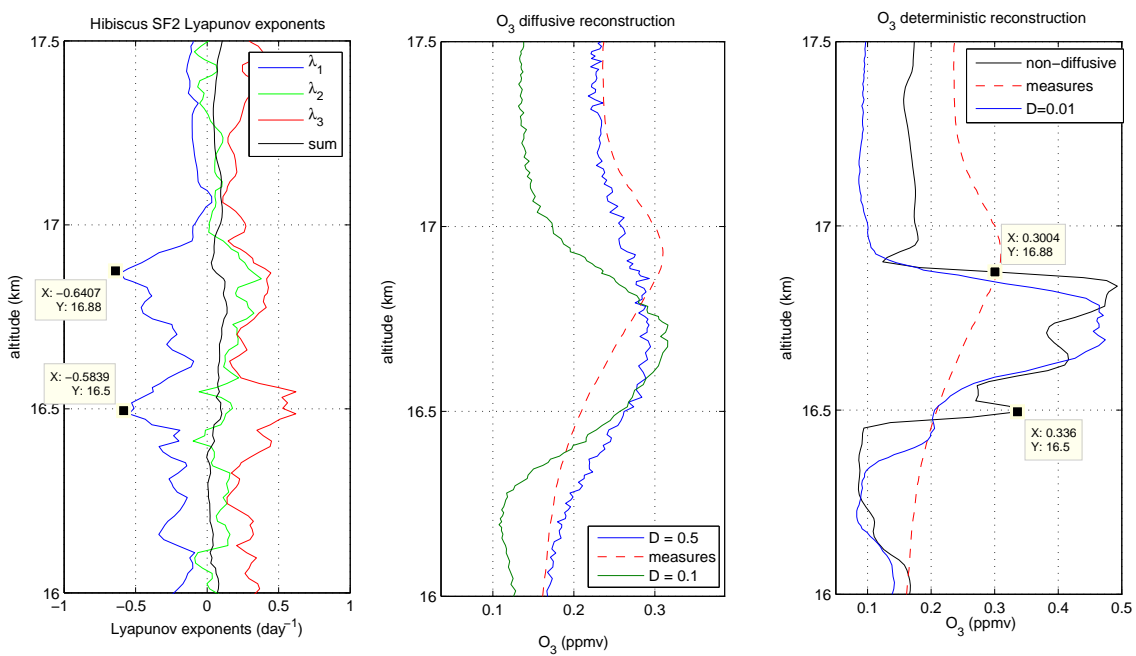

Fig. 11. Left panel: Three-dimensional Lyapunov exponents along SF2 balloon track. Blue curves show the largest rate of separation between two points for negative time (contraction in the positive time direction). Red curve shows the largest positive exponent, corresponding to contraction in negative time. Green curve shows the second exponent, which can be positive or negative. Black curve is the sum of the three exponents that should vanish for strictly incompressible flow but here slightly differs from zero due to compressibility and numerical errors. Centre panel: diffusive reconstructions of $\mathrm{O}_{3}$ mixing ratio. Right panel: weakly diffusive and non-diffusive reconstructions of $\mathrm{O}_{3}$ mixing ratio.

calculation. It is clear that gradients reconstructed in that way are unrealistic, but it is striking to find that the boundary of the high $\mathrm{O}_{3}$ region corresponds sharply to the peaks of the Lyapunov exponents.

Over the altitude range of the intrusion, one Lyapunov exponent is negative while the two others are positive with about the same magnitude. This indicates that stirring generates filaments in the negative time and pancakes or sheets in the positive time.

\section{Conclusions}

We have shown that laminated structures in the $\mathrm{O}_{3}$ profile found during the subtropical HIBISCUS campaign can be identified with a long-range extra-tropical intrusion associated with breaking Rossby waves across the subtropical barrier. This intrusion carries air that trajectories trace back to polar latitudes less than 10 days before.

The peaks in the $\mathrm{O}_{3}$ profile induced by extra-tropical intrusions are very well reconstructed during the active phase of the intrusion, when the large scale flow induces a clear separation between air masses. The reconstruction performs less well during the subsequent ageing stage when unmixed extra-tropical air is preserved as sloping sheets in the subtropics and when separation relies on meso-scale stirring and mixing which is less constrained by data assimilation and hence less predictable. However, even in that case, reconstructed profiles in the vicinity of the balloon track reproduce ozone peaks with amplitude and vertical location close to the observations.
The best estimated value of Lagrangian turbulent diffusivity is $0.5 \mathrm{~m}^{2} \mathrm{~s}^{-1}$ which is somewhat larger than that found at mid latitude in winter for the same levels $\left(0.1 \mathrm{~m}^{2} \mathrm{~s}^{-1}\right)$ (Legras et al., 2005).

The intrusion is fairly localised in altitude just above the level of the tropical tropopause and belongs to a range of altitude where meridional exchanges are favoured (Waugh, 1996).

The mid-height of the reconstructed intrusion does not vary with $D$. Both upper and lower edges and the maximum value are reconstructed with the same value of $D$ while sharp peaks of stretching occur on the edges. This suggests that $D$ cannot be solely related to the local strain rate unlike the common assumption in most current parameterization and in agreement with previous findings at higher latitudes (Legras et al., 2005).

The generality of results found here is, however, somewhat limited by the scarcity of the available dataset and clearly needs to be confirmed by analysis of data from future campaigns.

Acknowledgements. We acknowledge the O3SSS and the DMI teams for the ozone data and $\mathrm{G}$. Durry for $\mathrm{H}_{2} \mathrm{O}$ and methane data. We acknowledge F. Lefèvre for the REPROBUS simulations and G. Berthet for fruitful discussions. I. Pisso was supported by a fellowship of the Ecole Polytechnique.

Edited by: P. Haynes 


\section{References}

Aliwell, S. R., Halsall, J. F., Pratt, K. F. E., O'Sullivan, J., Jones, R. L., Cox, R. A., Utembe, S. R., Hansford, G. M., and Williams, D. E.: Ozone sensors based on $\mathrm{WO}_{3}$ : a model for sensor drift and a measurement correction method, Meas. Sci. Technol., 12, 684-690, 2001.

Balluch, M. G. and Haynes, P. H.: Quantification of lower stratospheric mixing processes using aircraft data, J. Geophys. Res., 102(D19), 23 487-23 504, doi:10.1029/97JD00607,1997.

Benettin, G., Galgani, G., Giorgilli, L., and Strelcyn, J.: Lyapunov characteristic exponents for smooth dynamical systems and for Hamiltonian systems; a method for computing all of them: I theory, Meccanica, 15, 9-30, 1980.

Del Castillo-Negrete, D. and Morrison, P.: Chaotic transport by Rossby waves in shear flow, Phys. Fluids A-Fluid, 5(4), 948965, 1993.

Dexheimer, D. and Bowman, K.: Lagrangian methods for climatological analysis of regional atmospheric transport, J. Appl. Meteorol., 43(4), 623-630, 2004.

Fortuin, J. P. F. and Kelder, H.: An ozone climatology based on ozonesonde and satellite measurements, J. Geophys. Res., 103(D24), 31 709-31 734, doi:10.1029/1998JD200008, 1998.

Hansford, G. M., Freshwater, R. A., Bosch, R. A., Cox, R. A., Jones, R. L., Pratt, K. F. E., and Williams, D. E.: A low cost instrument based on a solid state sensor for balloon-borne atmospheric $\mathrm{O}_{3}$ profile sounding, J. Environ. Monitor., 7(2), 158-162, 2005.

Haynes, P. H. and Anglade, J.: The vertical-scale cascade in atmospheric tracers due to large-scale differential advection, J. Atmos. Sci., 54(9), 1112-1136, 1997.

Haynes, P. H. and Shuckburgh, E.: Effective diffusivity as a diagnostic of atmospheric transport. Part II: troposphere and lower stratosphere, J. Geophys. Res., 105(D18), 22 795-22 810, doi: 10.1029/2000JD900092, 2000.

Hegglin, M. I., Brunner, D., Peter, T., Staehelin, J., Wirth, V., Hoor, P., and Fischer, H.: Determination of eddy diffusivity in the lowermost stratosphere, Geophys. Res. Lett., 32, L13812, doi: 10.1029/2005GL022495, 2005.

Highwood, E. J. and Hoskins, B. J.: The tropical tropopause, Q. J. Roy. Meteorol. Soc., 124(549), 1579-1604, 1998.

Holton, J. R., Haynes, P. H., MCIntyre, M. E., Douglass, A. R., Rood, R. B., and Pfister, L.: Stratosphere-troposphere exchange, Rev. Geophys., 33(4), 403-439, doi:10.1029/95RG02097, 1995.

Holzer, M. and Hall, T. M.: Transit-time and tracer-age distributions in geophysical flows, J. Atmos. Sci., 57(21), 3539-3558, 2000.

Issartel, J.-P. and Baverel, J.: Inverse transport for the verification of the Comprehensive Nuclear Test Ban Treaty, Atmos. Chem. Phys., 3, 475-486, 2003

Lefèvre, F., Brasseur, G. P., Folkins, I., Smith, A. K., and Simon, P.: Chemistry of the 1991-1992 stratospheric winter: three dimensional model simulations, J. Geophys. Res., 99, 8183-8195, doi:10.1029/93JD03476, 1994.

Lefèvre, F., Figarol, F., Carslaw, K. S., and Peter, T.: The 1997 Arctic ozone depletion quantified from three dimensional model simulations, Geophys. Res. Lett., 25(13), 2425-2428, doi:10.1029/ 98GL51812, 1998.
Legras, B., Pisso, I., Lefèvre, F., and Berthet, G.: Variability of the Lagrangian turbulent diffusion in the lower stratosphere, Atmos. Chem. Phys., 5, 1605-1622, 2005, http://www.atmos-chem-phys.net/5/1605/2005/.

McCormick, M. P. and Veiga, R. E.: SageII Measurements of early Pinatubo aerosols, Geophys. Res. Lett., 19(2), 155-158, doi:10. 1029/91GL02790, 1992.

Morse, P. M. and Feshbach, H.: Methods of theoretical physics, Mc-Graw-Hill, Part I, pp. 857-859, 1953.

Neu, J. L. and Plumb, R. A.: Age of air in a "leaky pipe" model of stratospheric transport, J. Geophys. Res., 104(D16), 1924319255, doi:10.1029/1999JD900251, 1999.

Pierrehumbert, R. T. and Yang, H.: Global chaotic mixing on isentropic surfaces, J. Atmos. Sci., 50(15), 2462-2480, 1993.

Pommereau, J., Garnier, A., Held, G., Gomes, A.-M., Goutail, F., Durry, G., Borchi, F., Hauchecorne, A., Cocquerez, P., Letrenne, G., Vial, F., Hertzog, A., Legras, B., Pisso, I., Pyle, J. A., Harris, N. R. P., Jones, R. L., Robinson, A., Hansford, G., Eden, L., Gardiner, T., Swann, N., Knudsen, B., Larsen, N., Nielsen, J., Christensen, T., Cairo, F., Pirre, M., Marecal, V., Huret, N., Riviere, E., Coe, H., Grosvenor, D., Edvarsen, K., Donfrancesco, G. D., Ricaud, P., Longo, K., and Freitas, S.: An overview of the HIBISCUS campaign, Atmos. Chem. Phys. Discuss., 7, 23892475, 2007, http://www.atmos-chem-phys-discuss.net/7/2389/2007/.

Rosenlof, K. H.III and McCormick, M. P.: Hemispheric asymmetries in water vapor and inferences about transport in the lower stratosphere, J. Geophys. Res., 102(D11), 13 213-13 234, doi: 10.1029/97JD00873, 1997.

Stohl, A., Forster, C., Frank, A., and Wotawa, G.: Technical note: The Lagrangian particle dispersion model FLEXPART version 6.2, Atmos. Chem. Phys., 5, 2461-2474, 2005

Sudo, K., Takahashi, M., and Akimoto, H.: Future changes in stratosphere-troposphere exchange and their impacts on future tropospheric ozone simulations, Geophys. Res. Lett., 30(24), 2256, doi:10.1029/2002GL016047, 2003.

Volk, C. M., Elkins, J. W., Fahey, D. W., and Salawitch, R. J.: Quantifying transport between the tropical and mid-latitude lower stratosphere, Science, 272, 1763-1768, 1996.

Waugh, D. W.: Seasonal variation of isentropic transport out of the tropical stratosphere, J. Geophys. Res., 101(D2), 4007-4024, doi:10.1029/95JD03160, 1996.

Waugh, D. W. and Polvani, L. M.: Climatology of intrusions into the tropical upper troposphere, Geophys. Res. Lett., 27(23), 3857-3860, doi:10.1029/2000GL012250, 2000.

Waugh, D. W., Plumb, R. A., and Polvani, L. M.: Nonlinear, barotropic response to a localized topographic forcing: Formation of a "Tropical Surf Zone" and its effect on interhemispheric propagation, J. Atmos. Sci., 54(11), 1401-1416, 1994.

Williams, D. E., Aliwell, S. R., Pratt, K. F. E., Caruana, D. J., Jones, R. L., Cox, R. A., Hansford, G. M., and Halsall, J.: Modelling the response of a tungsten oxide semiconductor as a gas sensor for the measurement of ozone, Meas. Sci. Technol., 13, 923-931, 2002.

Williamson, D. L.: Semi-Lagrangian moisture transport in the NMC spectral model, Tellus, 142A, 413-428, 1989. 